\title{
Management of Traumatic Lower-Eyelid Avulsion and Complete Loss of the Lacrimal Canaliculus: A Case Report
}

\author{
Gregor Hawlina Katarina Vergot \\ Eye Hospital, University Medical Centre Ljubljana, Ljubljana, Slovenia
}

\section{Keywords}

Eyelid · Trauma $\cdot$ Canalicular reconstruction $\cdot$ Mini Monoka $\cdot$ Hughes flap

\begin{abstract}
Eyelid injuries commonly occur as a result of blunt or sharp periocular trauma. When the medial canthal region is affected, injury can be associated with canalicular laceration or avulsion. Complete loss of the lacrimal canaliculus associated with epiphora is a challenging condition, and reconstruction often leads to poor and disappointing results. Surgical treatment of a patient following blunt facial trauma that resulted in medial avulsion of the lower eyelid with tissue loss is presented. A 72-year-old male patient presented with avulsion of the medial 2/3 of the left lower eyelid together with complete loss of the inferior canaliculus. Eyelid tissue was not preserved. The inferior canaliculus was reconstructed using a Mini Monoka ( $\mathrm{FCl}$ Ophthalmics), which was sutured under the caruncle and was enveloped with surrounding tissue. Loss of the lower eyelid tissue was substituted with a medially shifted Hughes flap and free skin transplant from the ipsilateral upper eyelid. The Hughes flap was divided after 2 weeks, while the Mini Monoka extruded spontaneously approximately 3 months after the injury. Ten months after the injury, the opening of the reconstructed lower canaliculus was positioned under the caruncle and was patent on probing and syringing. The patient is without epiphora and is satisfied with the functional and aesthetic result. In eyelid injuries we follow certain rules of reconstruction, but each case is unique and requires some inventiveness. The idea of inferior canalicular reconstruction following lower-eyelid avulsion with tissue loss is presented.
\end{abstract}




\section{Case Reports in Ophthalmology}

\section{Introduction}

Eyelid injury is a rather common medical condition in ophthalmology, requiring wellplanned and complex treatment to provide the best outcome and reduce the chances of postoperative complications. The most common causes of eyelid injury, which can be sharp or dull, are accidents, sports injuries, traffic accidents, dog bites, and injuries related to violence [14]. More often, lower eyelids are involved [1, 5, 6].

Eyelid avulsion is a type of injury where the part or the whole length of the eyelid has been torn from its normal anatomical position. The eyelid can be torn off from the orbit but can remain attached to the surrounding tissue, or it can be pulled out completely, and the tissue can be preserved or not $[2,4]$. Injuries with avulsed eyelids are frequently related to the damage of the area of the medial canthus, and thus to the damage of the excretory lacrimal system that is present in $16 \%$ of the patients with eyelid injuries. They most commonly cover the laceration or avulsion of the canaliculus. For the best treatment outcome, it is necessary to have an excellent knowledge of the anatomy of the affected area and to be familiar with specific surgical techniques $[1,6]$. The type of surgery depends on the amount of tissue retained. Complete loss of the lacrimal canaliculus with epiphora is a condition whose reconstruction often results in a poor outcome [5-10].

The purpose of this paper is to present the case and surgical treatment of a patient with an avulsed medial part of the lower eyelid with complete loss of the inferior canaliculus.

\section{Case Presentation}

A 72-year-old male patient fell and injured his left lower eyelid by hitting the edge of the stairs 1 day before arriving at the emergency clinic. The injury resulted in an avulsion of the medial 2/3 of the lower eyelid along with the entire length of the lower canaliculus (Fig. 1, 2). The patient did not bring the avulsed tissue with him.

On clinical examination, the eye globe and the eye muscles were intact, the visual acuity was appropriate, and X-ray imaging did not show associated skeleton damage. The lateral canthal region was undamaged. He received local and systemic antibiotic therapy and tetanus prophylaxis. Due to unavailability of the oculoplastic surgeon during weekend time, the reconstruction was performed 3 days after the injury. The rules for a successful reconstruction of the eyelids were considered [11] with the exception that the reconstruction of the missing lower eyelid was performed during primary repair due to exposition of the lower part of the cornea and possible development of expositional keratopathy. The surgical procedure was performed under general anesthesia. First revision of the wound was made, and fibrin linings were removed, which formed abundantly within only 3 days (Fig. 1a, b). In the next step, the bottom part of the lower fornix was reconstructed by suturing remnants of the damaged lower eyelid retractors and conjunctiva. Due to the absence of the entire lower canaliculus, it was reconstructed with the use of a Mini Monoka (FCI Ophthalmics, Marshfield Hills, MA), which was fixed under the caruncle approximately $6 \mathrm{~mm}$ laterally from the remnant of the lower canaliculus. The uncovered part of the Mini Monoka was enveloped with the surrounding tissue of the orbital septum, which was sutured to the deep layer of the fornix conjunctiva (Fig. 3).

The remaining eyelid defect, where both the anterior and posterior lamellae were absent, was reconstructed using a Hughes flap and free skin transplant from the ipsilateral upper eyelid. The size of the Hughes flap was horizontally slightly smaller than the lower eyelid defect and was shifted medially due to the position of the eyelid defect. Preparing the Hughes flap 
directly above an extremely medial eyelid defect is not possible due to the absence of the tarsal plate in the medial part of the upper eyelid and the possibility of iatrogenic damage to the upper canaliculus. The flap was sewn with resorbable sutures and was positioned medially above the newly reconstructed canaliculus. In the medial canthal area it was fixated on the remnants of the canthal tendon, laterally on the tarsal plate and inferior to the lower eyelid retractors.

In the last part of the surgical procedure, the anterior lamella was reconstructed using a free skin transplant from the ipsilateral upper eyelid. The skin was grafted by preforming an upper blepharoplasty procedure. The Hughes flap was split 14 days after the primary procedure. At separation, the conjunctival pedicle was cut, and the edges were cauterized (Fig. 4c).

One day after the procedure, the free skin transplant was appropriately positioned, and all wounds were sutured without dehiscence (Fig. 4a). One week after the procedure, the skin sutures were removed, and after 2 weeks, the Hughes flap was divided (Fig. 4b). Three weeks after the procedure, a small notch was seen between the medially positioned, newly reconstructed eyelid and the residual lateral part of the eyelid (Fig. 4c). At that time, the Mini Monoka was still in a proper position, fixated with sutures under the caruncle. The patient did not come to the follow-up visit at 3 months, but he later stated that the Mini Monoka extruded spontaneously at around that period. Ten months after the injury, the notch on the lower eyelid resolved (Fig. 4d), and the opening of the newly reconstructed lower canaliculus was positioned under the caruncle and was patent on probing and syringing. There was no retraction of the upper eyelid, which is a known and described complication after splitting a Hughes flap (Fig. 4d) [12, 13]. Slight medial ectropion developed, but the patient was asymptomatic and without epiphora. He was satisfied with the aesthetic and functional result.

\section{Discussion}

In the paper, we have presented an approach for the reconstruction of an avulsed lower eyelid with combined loss of the entire lower canaliculus. The described surgical management presents a useful alternative for the reconstruction of a lost lower canaliculus, which is performed with the surrounding tissue wrapped around the Mini Monoka.

The reconstruction of the lacrimal canalicular lacerations requires stenting. Various surgical techniques for the reconstruction and different materials for the intubation of the damaged canaliculus (both monocanalicular and bicanalicular) have already been described in the literature [8-10]. The bicanalicular method of intubation, which was more commonly used in the past, is nowadays surpassed by the monocanalicular method, since it represents a less invasive procedure [8]. The Mini Monoka is a widely popular monocanalicular stent. It is a simple, minimally invasive, and efficient tool for the reconstruction of traumatic canalicular lacerations. In comparison to the bicanalicular method, it avoids iatrogenic injury to the other uninjured part of the lacrimal drainage system. Many published papers describe surgical techniques for traumatic canalicular reconstruction when tissue is preserved [14-22]. However, there are only few reports about the reconstruction of a lost non-preserved canaliculus [5,23]. If just part of the canaliculus is lost due to an injury, resected during removal of an eyelid tumor or during repair of severe medial ectropion with marked laxity of the medial canthal tendon, the remaining section of the canaliculus can be exteriorized to the lacrimal lake [11,24]. On the other hand, when the entire canaliculus is lost, the reconstruction with buccal mucosa enveloping a silicone stent positioned between the anterior and posterior lamella has been recognized as a possible surgical option [5]. Chen et al. [23] described the method for the 


\section{Case Reports in Ophthalmology}

reconstruction of a lost lacrimal ductus by using xenogeneic bovine acellular dermal matrix for the outer support structure and a free conjunctival graft for the inner wall of a newly formed ductus. Such a method could also be used for the surgical management of missing lacrimal canaliculi. The results of such a challenging reconstruction are often unsuccessful and disappointing [5, 23]. Subsequent epiphora can be prevented by performing a conjunctivodacryocystorhinostomy (CDCR) with Jones tubes where a connection between the medial fornix and the nasal cavity is made. However, in our case, the remnant of the lower canaliculus was too short to be marsupialized into the conjunctival sac. Therefore, to lengthen the lower canaliculus, we decided to use a Mini Monoka, which we fixated under the caruncle approximately $6 \mathrm{~mm}$ from the remnant of the lower canaliculus (Fig. 3a). Surrounding tissue (orbital septum and conjunctiva) was then wrapped around the uncovered part of the Mini Monoka (Fig. 3b).

The optimal time for the removal of lacrimal stents is still under debate [7, 8, 25-27]. Different authors suggest that the canaliculus should remain stented for 3-12 months after injury. In our case, the stent was spontaneously extruded approximately 3 months after reconstruction, which equals the time that we planned for explantation. The reconstructed missing part of the lower canaliculus was patent on probing and syringing 10 months after the injury. This proves that tissues around the Mini Monoka transformed into approximately 6-mm-long patent fistula.

There are several methods that may be applied for the reconstruction of full-thickness eyelid defects. The approach is similar whatever the cause. The way in which the full-thickness eyelid defect is reconstructed depends on the length of the lost part of the eyelid. When losing half of the length or more, the tissues should be replaced $[1,5,6]$. In our case, according to the location and size of the defect, we reconstructed the eyelid with a medially shifted Hughes flap, which supported the free skin graft from the ipsilateral upper eyelid.

The rules for a successful reconstruction of eyelids were considered in our case, with the exception that we reconstructed the missing part of the lower eyelid and added the tissue during primary repair. According to the literature, a major reconstruction should be delayed for 3,6 , or even 9 months for the wound to settle unless the cornea is seriously at risk [11]. Since the wound was clean and there was a risk for the development of expositional keratopathy, we decided to perform eyelid reconstruction during primary repair. According to our observations, the fibrin linings that intensively formed within only 3 days (Fig. 1a, b) caused obvious retraction of the remnant of the lateral part of the lower eyelid. This changed the anatomy of the tarsal plate and retractors. Thus, in our opinion, late reconstruction of the eyelid would be more challenging than early reconstruction due to retraction and scarring of tissues. The method we selected for canalicular reconstruction was successful but should still be evaluated in more patients. The surgical management is potentially applicable also for reconstructions after removal of tumors in this region, or when dealing with canalicular stenosis of iatrogenic or congenital etiology. Due to a relatively uncomplicated canalicular reconstruction, which does not require grafting of additional tissues as described in previous papers [5, 23], we recommend trying to reconstruct the canaliculus in selected cases using the described method. If this method fails, later use of more demanding surgical methods [5, 23] or performing CDCR using a Jones tube in symptomatic patients is still possible. 


\section{Conclusion}

In eyelid injuries, we follow certain rules of reconstruction. However, each case is unique and requires some inventiveness. The reconstruction of a lost, non-preserved canaliculus is a challenging procedure with frequently unsuccessful results that later require CDCR. The idea of canalicular reconstruction following lower-eyelid avulsion with tissue loss was presented. When the entire canaliculus is lost, the surgical method in which the Mini Monoka is enveloped with the surrounding tissue of the orbital septum and deep layer of the fornix conjunctiva presents a promising option for canalicular reconstruction.

\section{Statement of Ethics}

The authors have no ethical conflicts to disclose. The patient gave his written informed consent to publish his case (including the publication of images).

\section{Disclosure Statement}

The authors have no conflicts of interest to declare.

\section{Funding Sources}

The authors received no funding or grant support.

\section{Author Contributions}

Gregor Hawlina was the primary author and was involved in the surgical management of the patient and manuscript preparation as well as editing. Katarina Vergot was involved in manuscript preparation and editing.

\section{References}

1 Bowling B. Kanski's Clinical Ophthalmology: A Systematic Approach. 8th ed. Philadelphia: Elsevier; 2016.

2 Pauly M, Naik M, Abraham PS, Anantharaman G. Eyelid avulsion managed with composite autograft in a 6year-old child. Kerala J Ophthalmol. 2017;29(1):49-50.

3 Denniston AK, Murray PI. Oxford Handbook of Ophthalmology. 2nd ed. New York: OUP Oxford; 2009.

4 Goldberg SH, Bullock JD, Connelly PJ. Eyelid avulsion: a clinical and experimental study. Ophthal Plast Reconstr Surg. 1992;8(4):256-61.

5 Lo Torto F, Losco L, Bernardini N, Greco M, Scuderi G, Ribuffo D. Surgical Treatment with Locoregional Flaps for the Eyelid: A Review. BioMed Res Int. 2017;2017:6742537.

6 Subramanian N. Reconstructions of eyelid defects. Indian J Plast Surg. 2011 Jan;44(1):5-13.

7 Czyz CN, Cahill KV, Foster JA, Michels KS, Clark CM, Rich NE. Reconstructive options for the medial canthus and eyelids following tumor excision. Saudi J Ophthalmol. 2011 Jan;25(1):67-74.

8 Sendul SY, Cagatay HH, Dirim B, Demir M, Cinar S, Ucgul C, et al. Reconstructions of Traumatic Lacrimal Canalicular Lacerations: A 5 Years Experience. Open Access J Sci Technol. 2015;3:1-6.

9 Tint NL, Alexander P, Cook AE, Leatherbarrow B. Eyelid avulsion repair with bi-canalicular silicone stenting without medial canthal tendon reconstruction. Br J Ophthalmol. 2011 Oct;95(10):1389-92. 


\section{Case Reports in Ophthalmology}

\begin{tabular}{l|l}
\hline Case Rep Ophthalmol 2019;10:172-179 \\
\hline DOI: 10.1159/000500237 & $\begin{array}{l}\text { @ 2019 The Author(s). Published by S. Karger AG, Basel } \\
\text { www.karger.com/cop }\end{array}$ \\
\hline
\end{tabular}

Hawlina and Vergot: Management of Traumatic Lower-Eyelid Avulsion and Complete Loss of the Lacrimal Canaliculus: A Case Report

10 Kurihashi K. Canalicular reconstruction for difficult cases: lacrimal stents and multiple traction sutures. Ophthalmologica. 1995;209(1):27-36.

11 Collin JR. A Manual of Systematic Eyelid Surgery. 3rd ed. United Kingdom: Elsevier Limited; 2006.

12 Hishmi AM, Koch KR, Matthaei M, Bölke E, Cursiefen C, Heindl LM. Modified Hughes procedure for reconstruction of large full-thickness lower eyelid defects following tumor resection. Eur J Med Res. 2016 Jun;21(1):27.

13 Hausheer JR. Basic techniques of ophthalmic surgery. 2nd ed. San Francisco: American Academy of Ophthalmology; 2015

14 Tao H, Wang P, Han C, Zhang J, Bai F, He ZY. One-stitch anastomosis through the skin with bicanalicular intubation: a modified approach for repair of bicanalicular laceration. Int J Ophthalmol. 2013 0ct;6(5):6568.

15 Bi Y, Sui G, Zhou Q, Heindl LM, Bock F, Sun X, et al. Two-step retrograde closed stenting: a novel method for treating canalicular lacerations in Chinese patients. Eye (Lond). 2013 Nov;27(11):1275-80.

16 Veirs ER. Malleable rods for immediate repair of the traumatically severed lacrimal canaliculus. Trans Am Acad Ophthalmol Otolaryngol. 1962 Mar-Apr;66:263-4.

17 Kaufman HE, Chapman RB. Modified probe for canaliculus surgery. Am J Ophthalmol. 1962 Sep;54(3):461-2.

18 Griffith TP. Polythene Tubes in Canaliculus Surgery. Br J Ophthalmol. 1963 Apr;47(4):203-10.

19 Smith B, Dodick JM. Repair of lid lacerations involving the lower lacrimal canaliculus. Can J Ophthalmol. 1968 Jul;3(3):263-5.

20 Simons JN. Useful instrument for repair of lacerated lacrimal canaliculus. Plast Reconstr Surg. 1969 Jan;43(1):78-80.

21 Fountain TR. Management of Canalicular Trauma. In: Levine MR, editor. Manual of Oculoplastic Surgery. 4th ed. United States: Slack Inc; 2010. pp. 33-8.

22 Hawes MJ, Dortzbach RK, Segrest DR. Lacrimal Canalicular Trauma. In: Dr K, editor. Ophthalmic Plastic Surgery: Prevention and Management of Complications. New York: Raven Press. Ltd.; 1994. pp. 225-35.

23 Chen L, Gong B, Wu Z, Jetton J, Chen R, Qu C. A new method using xenogeneicacellular dermal matrix in the reconstruction of lacrimal drainage. Br J Ophthalmol. 2014 Nov;98(11):1583-7.

24 Older JJ. Treatment of the lacrimal excretory system after resection of medial canthal and eyelid tumors. Ophthalmic Surg. 1979 Jun;10(6):29-34.

25 Kersten RC, Kulwin DR. “One-stitch" canalicular repair. A simplified approach for repair of canalicular laceration. Ophthalmology. 1996 May;103(5):785-9.

26 Liang T, Zhao GQ, Li YL, Yang SS, Zhang LY, Wu Y. Efficiency and therapeutic effect of modified pigtail probe in anastomosing lacerated lacrimal canaliculus. Chin J Traumatol. 2009 Apr;12(2):87-91.

27 Drnovšek-Olup B, Beltram M. Trauma of the lacrimal drainage system: retrospective study of 32 patients. Croat Med J. 2004 Jun;45(3):292-4.
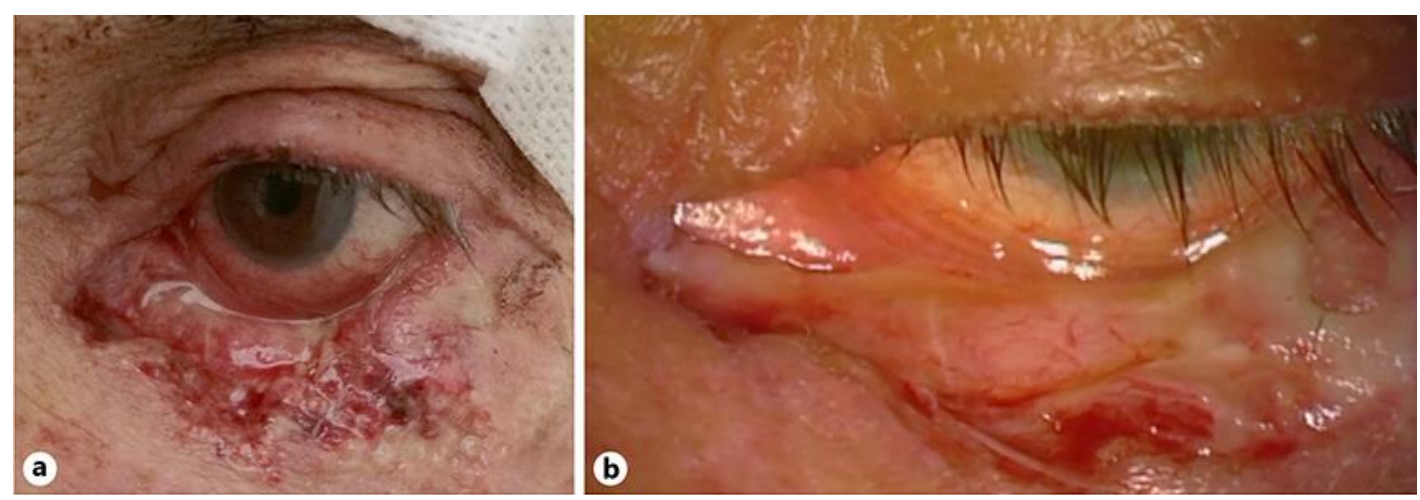

Fig. 1. Preoperative pictures of the patient's lower eyelid. a One day after injury, on the day of admission. b Three days after the injury, just before surgery. The medial $2 / 3$ of the eyelid is missing, together with the full length of the lower canaliculus. 


\section{Case Reports in Ophthalmology}

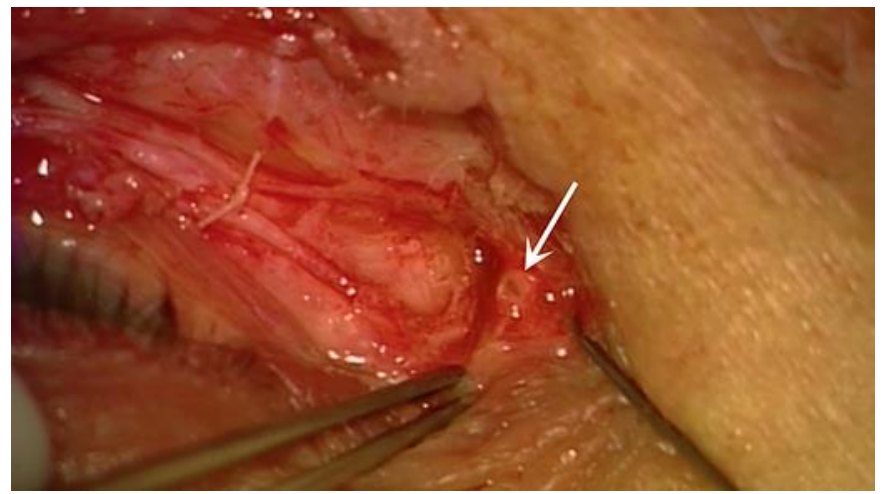

Fig. 2. The remnant of the lower canaliculus (pointed by an arrow) was positioned extremely proximally and was too short to be simply marsupialized into the conjunctival sac.
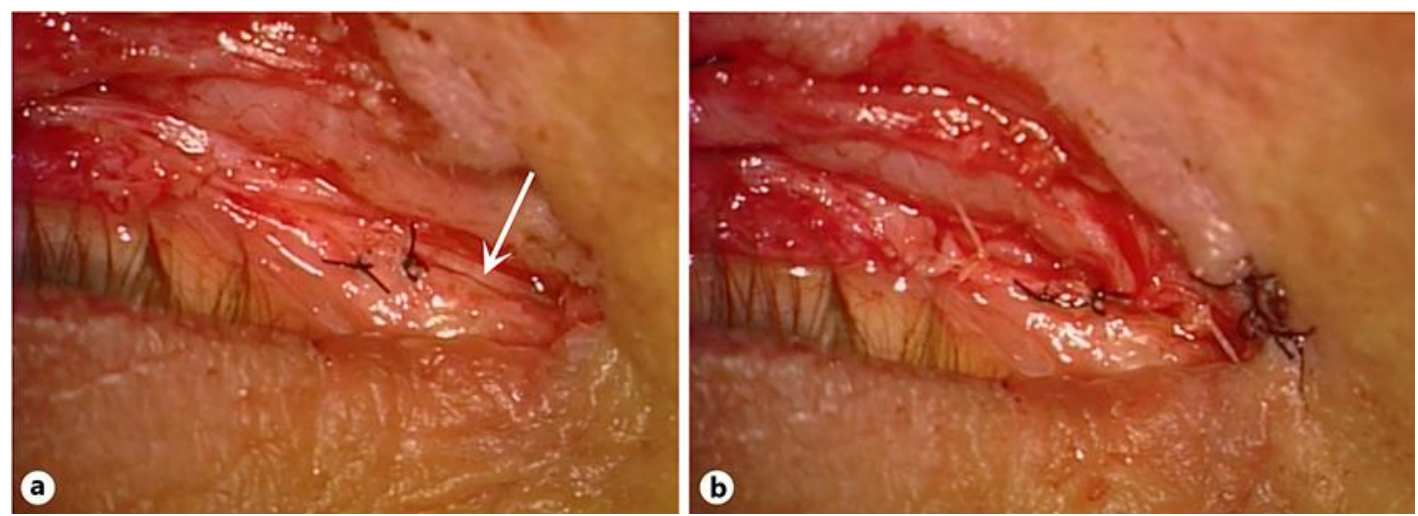

Fig. 3. a A Mini Monoka (pointed by an arrow) was fixated with sutures (silk of black color) under the caruncle. b The fixated Mini Monoka was enveloped with the orbital septum, which was sutured to the deep layer of the fornix conjunctiva. 


\section{Case Reports in Ophthalmology}
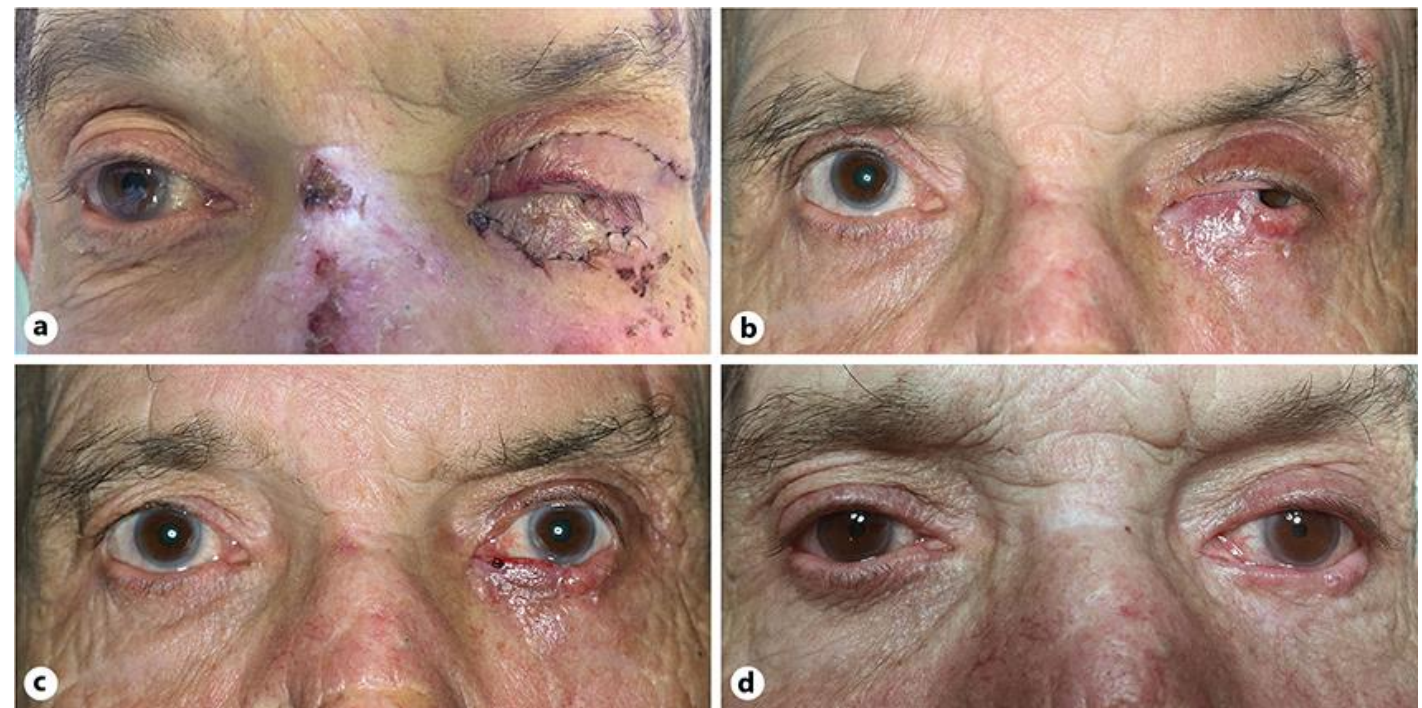

Fig. 4. Pictures of the patient 1 day after the procedure (a), 14 days after the procedure (b), 21 days after the procedure $(\mathbf{c})$, and 10 months after the procedure (d). 